\title{
Surgical Management of Intussusception in Children: A Retrospective Review of 212 Cases
}

\author{
Rajendra K. Ghritlaharey ${ }^{1, \odot}$ \\ ${ }^{1}$ Department of Pediatric Surgery, Gandhi Medical College and \\ Associated Kamla Nehru and Hamidia Hospitals, Bhopal, Madhya \\ Pradesh, India
}

\begin{abstract}
Address for correspondence Rajendra K. Ghritlaharey, MS, MCh, FAIS, MAMS, DLitt, Department of Pediatric Surgery, Gandhi Medical College and Associated Kamla Nehru and Hamidia Hospitals, Bhopal 462001, Madhya Pradesh, India (e-mail: drrajendrak1@rediffmail.com).
\end{abstract}

\author{
Abstract \\ Keywords \\ - children \\ - infant \\ - intestinal obstruction \\ - intussusception \\ - bowel gangrene \\ - pathological lead \\ point
}

Objectives The primary objective of this study was to analyze and review the demographics of children operated upon for intussusception. Secondary objectives were to review the clinical characteristics, surgical procedures performed, postoperative complications, and outcome.

Materials and Methods It is a single-institution, retrospective study and consists of children below the age of 12 years. This study was conducted at the author's department of pediatric surgery for the past 21 years, from January 1, 2000 to December 31, 2020. Results During the study period, 212 children were operated upon for intussusceptions and included $146(68.86 \%)$ boys and 66 (31.13\%) girls. This review consisted of infants $158(74.52 \%)$, and children of 1 to 5 years of age (30;14.15\%), and 6 to 12 years of age $(24 ; 11.32 \%)$. Clinically, $177(83.49 \%)$ children presented with the features of acute intestinal obstruction, and the remaining 35 (16.5\%) presented with features of perforation peritonitis. Primary (idiopathic) intussusception was documented in $188(88.67 \%)$ of the cases. Gangrenous bowel was evident in $98(46.22 \%)$ children. Sixty-two percent of the cases required bowel resection. Surgical procedures were executed in children for intussusception in the following order of frequency: (1) operative reduction with or without serosal tear/bowel perforation repair, $n=81$ (38.2\%); (2) resection of diseased ileum and ileoileal anastomosis, $n=52$ (24.52\%); (3) resection of diseased ileum \pm part of colon and an ileostomy, $n=36$ (16.98\%); and (4) resection of diseased ileum, cecum, part of colon, and ileocolic (ileo-ascending or ileo-transverse) anastomosis, $n=43$ (20.28\%). Postoperatively, 9 (4.24\%) children required reexploration for the management of their complications. Twenty-one (9.9\%) children died during the postoperative period.

Conclusion Intussusception remains the most common cause of acute intestinal obstruction in infants and young children. Delay in the referral, diagnosis, and seeking treatment were significantly associated with bowel gangrene, required bowel resection during the surgical therapy, and also culminated in significantly higher mortalities. published online October 26, 2021
DOI https://doi.org/

$10.1055 / \mathrm{s}-0041-1739034$ ISSN 0379-038X (c) 2021. National Academy of Medical Sciences (India).

This is an open access article published by Thieme under the terms of the Creative Commons Attribution-NonDerivative-NonCommercial-License, permitting copying and reproduction so long as the original work is given appropriate credit. Contents may not be used for commercial purposes, or adapted, remixed, transformed or built upon. (https://creativecommons.org/licenses/by-nc-nd/4.0/).

Thieme Medical and Scientific Publishers Pvt. Ltd. A-12, 2nd Floor, Sector 2, Noida-201301 UP, India 


\section{Introduction}

Intussusception is one of the most frequent causes of acute intestinal obstruction in infants and young children. ${ }^{1-4}$ It also occurs in older children and adults; however, the incidence of intussusception is extremely low in adults. ${ }^{4,5}$ Intussusception occurs more frequently in males as compared with fema les. ${ }^{3,4,6-8}$ Primary (idiopathic) intussusceptions is reported in approximately $95 \%$ of the cases in infants and younger children. ${ }^{8}$ Secondary intussusception occurs in 1.5 to $15 \%$ of the cases, and it is more frequent in older children. ${ }^{8-10}$ The treatment of choice for intussusception in children is currently nonsurgical with radiological reduction under sonographic or fluoroscopic control. ${ }^{1,6-8}$ In developing countries, surgical therapy is frequently employed as the primary option for managing infants and children with intussusception due to the delayed presentation and presence of bowel gangrene. ${ }^{11-14}$ Mortality relating to the management of intussusception in infants and children is less than $1 \%$ in the developed countries. ${ }^{2,7,8}$ In developing countries, management of intussusception in infants and children is associated with considerably higher mortality. ${ }^{2,11-14}$ Present study consisted of 212 children below the age of 12 -years, who were operated upon for intussusception during the study period of 21 years, with a brief review of the literature.

\section{Materials and Methods}

It is a single-institution and retrospective study. It included children below the age of 12 years, who were operated upon for the intussusception during the study period. This study was performed during the past 21 years, from January 1 , 2000 to December 31,2020. This study was conducted at the author's department of pediatric surgery during the abovementioned period. Case records of all the children who were operated upon for intussusception were reviewed for their demographics, clinical characteristics, surgical procedures performed, postoperative complications, and final outcome.
Institutional ethics committee approval was obtained for the waiver of the consent, and it was exempted from the review because of the retrospective nature of the study.

\section{Results}

During the study period, 212 children were operated upon for intussusception. The distribution of age and sex of children operated for intussusception is provided in $\boldsymbol{\sim}$ Fig. $\mathbf{1}$. The month-wise distribution of intussusception cases in children is provided in - Fig. 2. Clinically, 177 (83.49\%) children presented with the features of acute intestinal obstruction, and the remaining 35 (16.5\%) children presented with the features of perforation peritonitis. Plain skiagram and ultrasonography (USG) of the abdomen were the radiological investigations done for entire cases. Other basic hematological and biochemical investigations were also obtained. Preoperative diagnosis of intussusception was possible in 156 (73.58\%) children. Surgical procedures executed for the management of intussusception in children are detailed in - Fig. 3. During operative procedures, gangrenous bowels were documented in $98(46.22 \%)$ children. During the postoperative period, $n$ $=9(4.24 \%)$ children required reexploration for management of their complications. This study also documented $n=21$ (9.9\%) deaths that occurred during the postoperative period. The demographics and other details of children who died during the postoperative period are detailed in $\boldsymbol{- T a b l e} \mathbf{1}$.

\section{Discussion}

Intussusception was first time mentioned as the intestinal invagination by Paul Barbette in $1674 . .^{15,16}$ The first successful operation for intussusception was performed upon in an adult by Cornelius Henrik Velse, which he reported in $1742 .{ }^{17,18}$ The first successful operative reduction of intussusception was performed in the United States of America by Dr. John R. Wilson in December $1831 .{ }^{19}$ Sir Jonathan

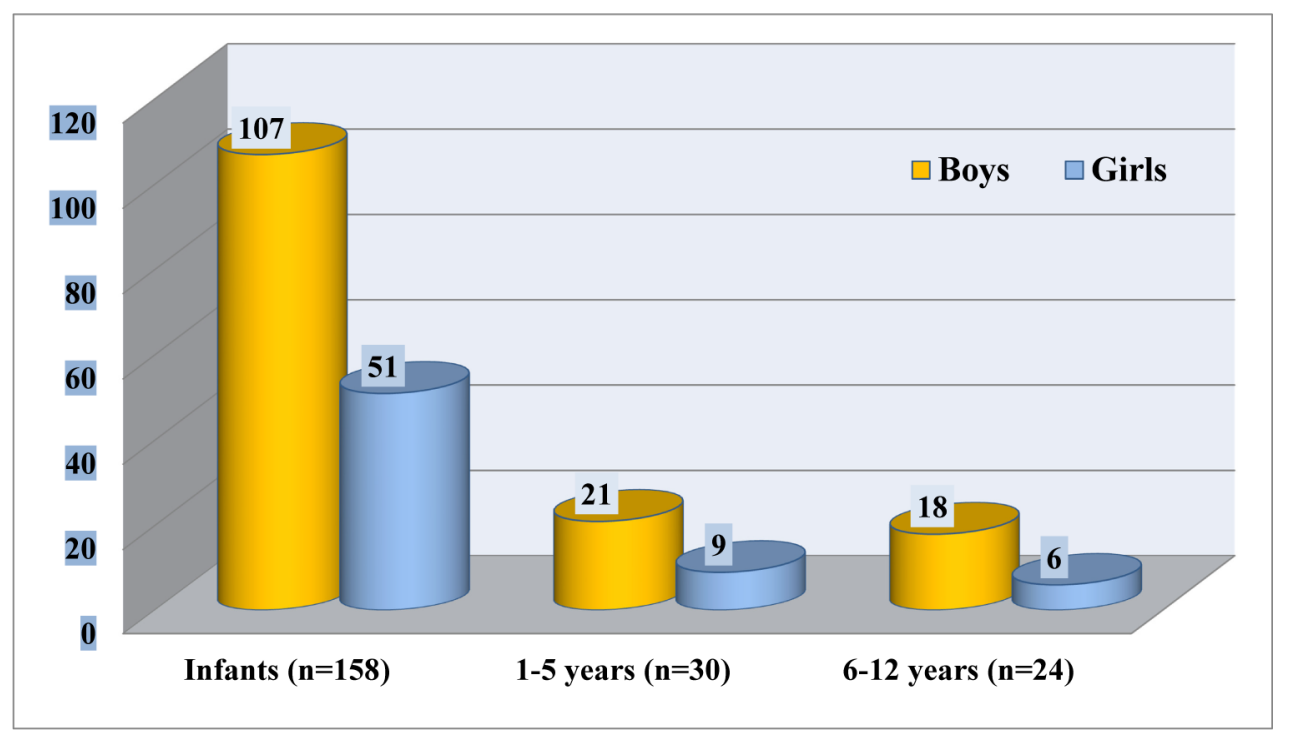

Fig. 1 Age and sex distribution of children operated for intussusception. 


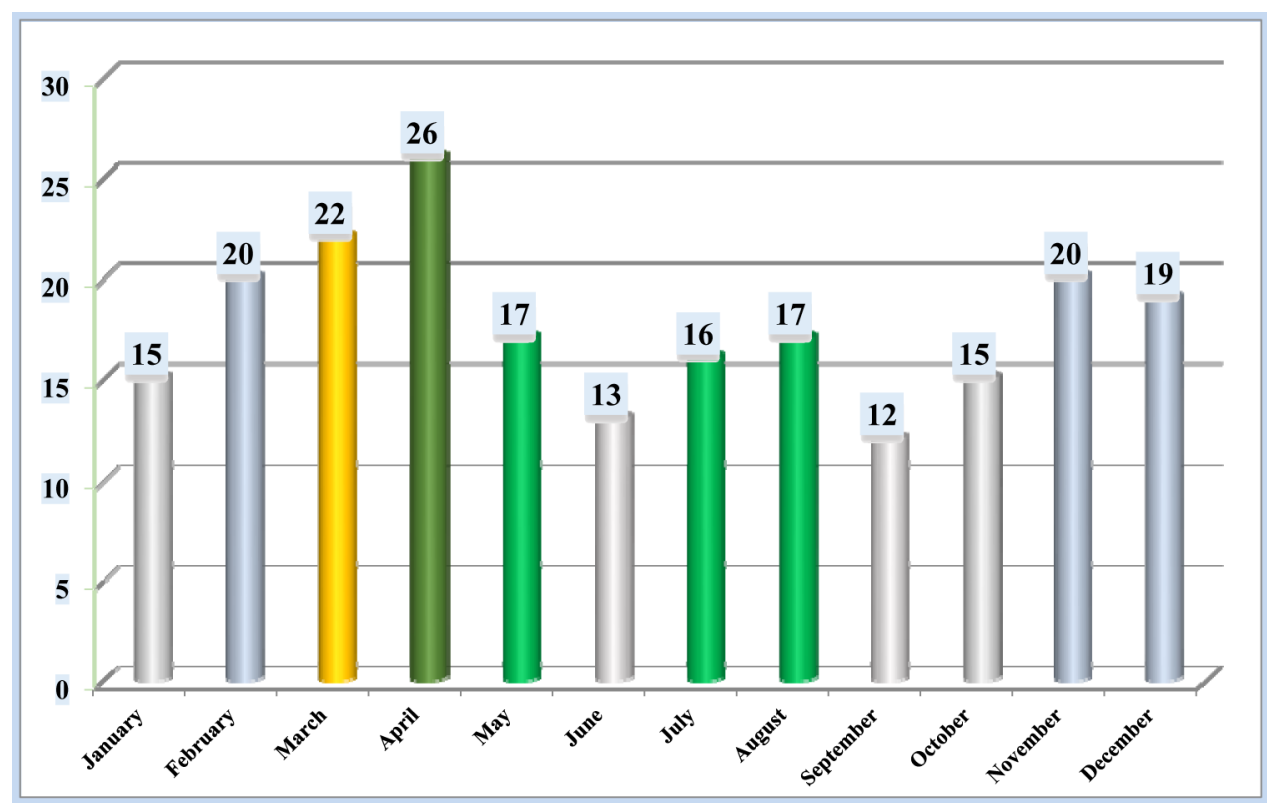

Fig. 2 Month-wise distribution of intussusception cases in children.

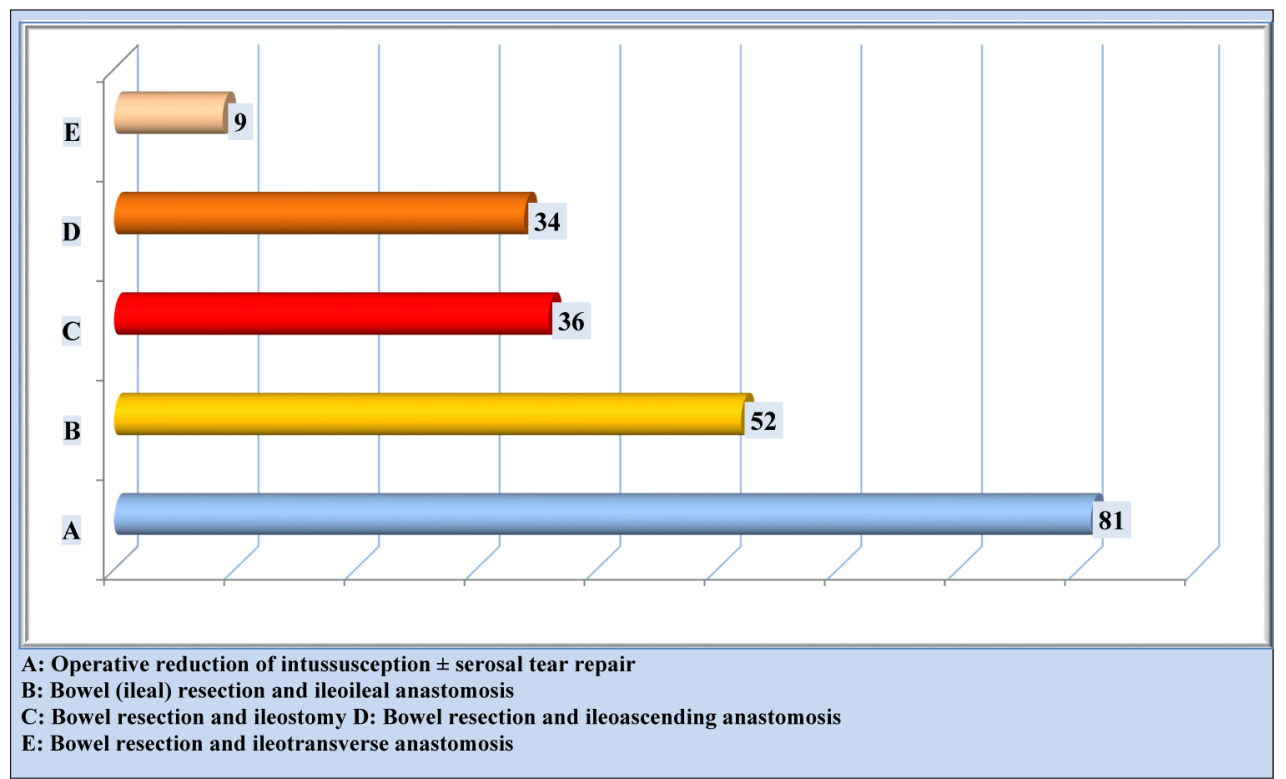

Fig. 3 Operative procedures performed for the management of intussusception in children.

Hutchinson, reported the first successful laparotomy and reduction of an ileocolic intussusception on a 2-year-old girl in 1871, and the same was published in $1874 .^{20,21}$ Harald Hirschsprung in 1876, and thereafter in 1905, published his experience with the nonoperative, hydrostatic enema reduction of intussusception in children. He concluded that the mortality of the above therapy for intussusception in children was only $30 \% .^{22,23}$

The present review of $n=212$ children with intussusception revealed that $85 \%$ of children were less than 3 years, and three-fourths of them were infants. In children, intussusception occurs most frequently during infancy and within 2 years of life. ${ }^{1-4}$ It also occurs in the older children; however, the incidence of intussusception is less. The findings similar to the present study were also documented in various studies done for childhood intussusception. ${ }^{2,24,25}$ Simon et al in a retrospective review, and Savoie et al in a review of pediatric health information system database revealed that $90 \%$ intussusception cases were $\leq 3$ years of age..$^{26,27}$

The present study documented that more than two-thirds of intussusception cases occurred in boys, with a male-to-female ratio of 2.2:1. Three-fourths of intussusception cases occurred during infancy. Other studies relating to childhood intussusception also documented that it also occurred more in males, with a male-to-female ratio of 1.6 to 3:1.,4,6-8,24-26 Das et al, in a retrospective surveillance study of 1,588 intussusception cases in children below 2 years of age, found that $68.6 \%$ of the cases were boys. ${ }^{6}$ 
Intussusception in Infants and Children Ghritlaharey

229

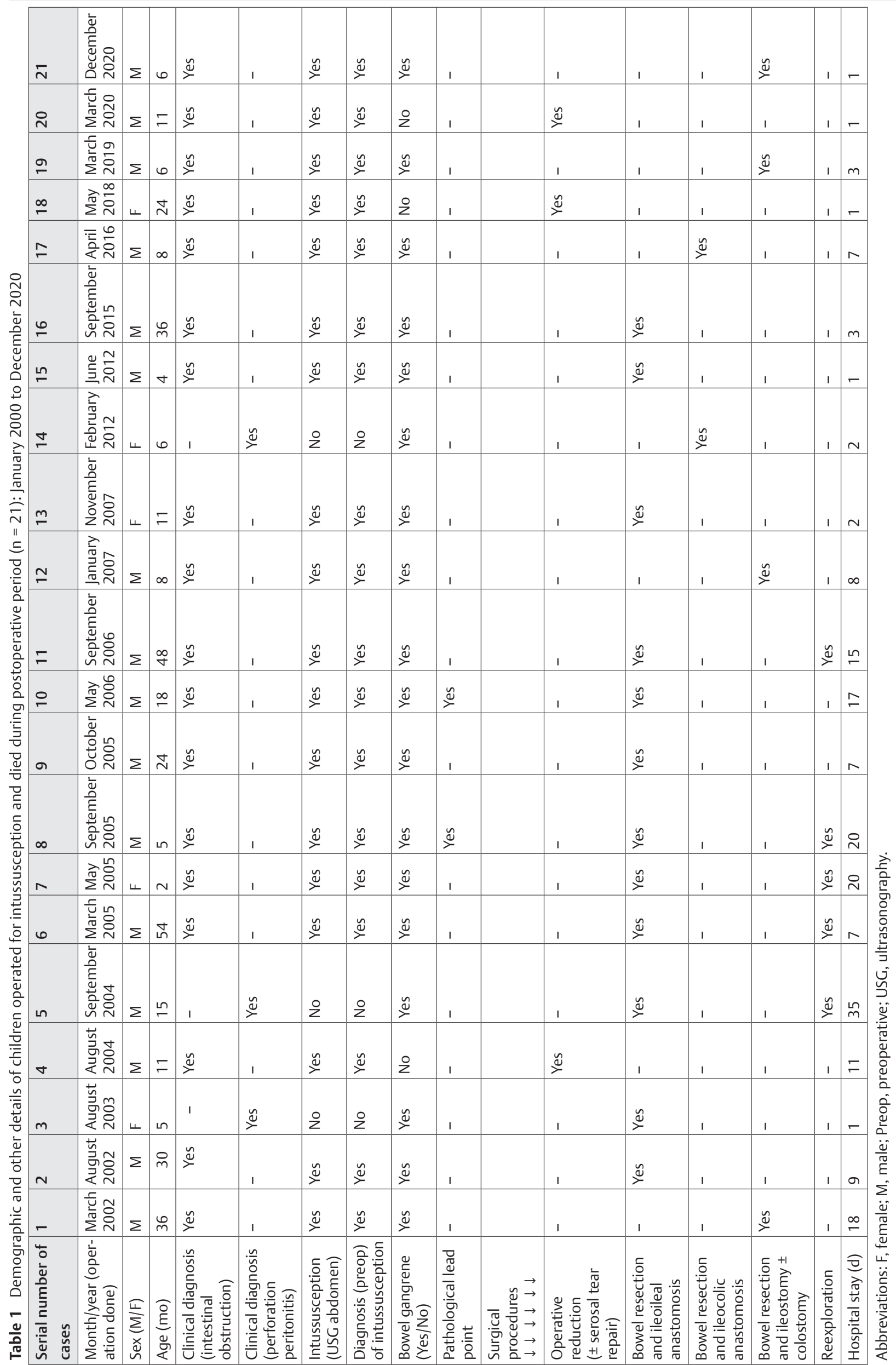

Annals of the National Academy of Medical Sciences (India) Vol. 57 No. 4/2021 @ 2021. National Academy of Medical Sciences (India). 
The most common symptoms and signs for childhood intussusception are vomiting, abdominal pain, abdominal mass, and blood mixed stools, and it occurs in various

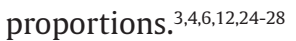

The classic triad of intussusception consists of two symptoms (abdominal pain and vomiting) and one sign (blood/mucoid stool), and that was evident in $n=180$ (84.9\%) children in the present study. The classic four for intussusception consists of two symptoms (abdominal pain and vomiting) and two signs (abdominal mass and blood/mucoid stool), and that was evident in $n=150$ (70.75\%) children of present study. More than four-fifths of children presented with the features of intestinal obstructions in the present study.

USG of the abdomen is a well-established and investigation of choice for the diagnosis of childhood intussusception and can diagnose more than $90 \%$ of the cases..$^{1,3,6,29-31}$ In the present study, skiagram and USG of the abdomen showed features suggestive of intestinal obstruction in 177 (83.4\%) children, while gas under the diaphragm was evident in 35 (16.5\%) children. All the secondary intussusception cases were diagnosed as intestinal obstruction due to intussusception during the abdominal evaluation by USG. Pathological lead points (PLPs) were not detected during the abdominal USG in any of the secondary intussusception cases.

In children, secondary intussusception occurs in approximately 1.5 to $15 \%$ and is reported more frequently in older children. ${ }^{5,8-12,24,29,32}$ Meckel's diverticulum is the most common pathology for secondary intussusception, including the present study. Other PLPs are ileal growth, ileal polyp, intestinal duplication, duplication cyst, lymphoma, cecal tumor, Peutz-Jeghers syndrome, and appendicular stump. ${ }^{8-11}$ PLPs causing secondary intussusception can be of mucosal, intramural, or extrinsic origin. In the present study, the incidence of secondary intussusception was $11.3 \%$, and PLPs responsible for secondary intussusception were Meckel's diverticulum $(n=18)$, benign ileal growth $(n=4)$, ileal polyp ( $n=1)$, and cecal carcinoma $(n=1)$.

Currently, the primary modality for management of childhood intussusception is nonoperative hydrostatic or pneumatic reduction under radiological/USG guidance with the added advantage of being nonoperative and being associated with a shorter hospital stay, and lower morbidity. Abovementioned therapy is practiced mostly in the developed countries with a success rate of over $95 \%$, and it is directly related to the early presentation and diagnosis of intussusception. ${ }^{17,8,33}$ In developed countries, surgical therapy with operative reduction or bowel resection for intussusception is employed for children who failed radiological reduction, presenting with bowel perforation, peritonitis, bowel gangrene, and children with a preoperative diagnosis of secondary intussusception. . $^{1,8,10,25,30,34}$

In developing countries, surgical therapy is more frequently employed as the primary modality for the management of childhood intussusception with the requirement for surgical therapy being reserved for cases with the late presentation, delayed referral, and suspected bowel gangrene. ${ }^{11-14}$ Present review included children with intussusception, who were primarily managed by surgical therapy, irrespective of their age, sex, and duration, clinical, and radiological findings. An ileocolic/colo-colic intussusception was the most common anatomical type, and it was documented in $n=183$ (86.32\%) of children, followed by the ileoileal, $n=27$ (12.73\%), jejuno-jejunal, $n=1(0.47 \%)$, and postoperative type, $n=1(0.47 \%)$. Primary (idiopathic) intussusception was observed in $n=188$ (88.67\%), and PLPs were documented for secondary intussusception in remaining $n=$ $24(11.32 \%)$ children. During operative procedures, gangrenous bowel segments were documented in $n=98$ (46.22\%) children. Sixty-two percent of children required bowel resections for the management of intussusception. It was possible to reduce intussusception in $38 \%$ children, and formal bowel resections were not required. Half of them had a serosal tear, minor perforation, or patchy bowel gangrenes, which were managed with serosal tear repair or bowel repair.

Complications are known to occur with the various surgical therapies employed for the management of childhood intussusception. These complications are peritoneal abscess, anastomotic leakage, peritonitis, wound dehiscence, postoperative adhesion, and incisional hernia. Some of them required reexploration for the management of their complications. ${ }^{11,14}$ Nine $(4.24 \%)$ children of the present study also required reexploration for the management of their complications. The postoperative complications that required reexploration were anastomotic leak, burst abdomen, wound dehiscence, and stoma necrosis.

In developed countries, mortality for the management of intussusception in infants and children is less than $1 \%$, and it is directly attributed to the early diagnosis, and institution of nonsurgical, radiological reduction of intussusception. Furthermore, mortality relating to the surgical treatment for childhood intussusception is also reported in less than $1 \%$ in the developed countries. ${ }^{2,7.8}$ Contrary to the above, in developing countries, mortality associated with the management of intussusception in infants and children is considerably higher, that is 7 to $10 \%$, including the present study. It is directly attributed to the delayed presentation, delay in referral and diagnosis, presence of bowel gangrene, frequent requirement of bowel resection, and frequent institution of surgical therapy. ${ }^{2,11-14}$ The present study observed $n=21$ (9.9\%) death that occurred during the postoperative period. Among the 21 children who died, 18 of them had gangrenous bowel and required bowel resections during the surgical management.

Twelve of 21 children who died were infants. Five children also required reexploration for the management of their complications. Nine children died within 24 to 72 hours after the surgical therapy, and death was attributed to the preoperative poor general condition.

Intussusception remains the most common cause of acute intestinal obstruction in infants and young children. Three-fourths of intussusception occurred during infancy. The present study also supports that intussusception occurs more in male children. Four-fifths of them presented with the features of acute intestinal obstruction. Primary intussusception was documented in $88 \%$ of children. During surgical therapy, gangrenous bowels were documented in $46 \%$ of children. 
Sixty-two percent children required bowel resection for the management of intussusception. For childhood intussusception, delay in referral, diagnosis, and seeking treatment were significantly associated with presence of bowel gangrene, requirement of bowel resections during the surgical therapy, factors that were responsible for significantly higher mortalities.

\section{Note}

This study was presented during e-MPASICON 2021 held online from March 24 to 26, 2021.

\section{Conflict of Interest}

None declared.

\section{References}

1 Columbani PM, Scholz S, Intussusception In: Coran AG, Adzick NS, Krummel TM, Laberge, et al. eds In: Pediatric Surgery. 7th ed. Philadelphia, PA: Elsevier Inc; 2012 1093-1110

2 Clark AD, Hasso-Agopsowicz M, Kraus MW, et al. Update on the global epidemiology of intussusception: a systematic review of incidence rates, age distributions and case-fatality ratios among children aged $<5$ years, before the introduction of rotavirus vaccination. Int J Epidemiol 2019;48(4):1316-1326

3 Cui P, Liu N, Li J, et al. Epidemiology of intussusception related hospitalizations in children aged $<2$ years in Suzhou, 2007-2013 [in Chinese]. Zhonghua Liu Xing Bing Xue Za Zhi 2016;37(3):410-414

4 Hsiao CC, Tsao LY, Lai CH. Nationwide population-based epidemiologic study of childhood and adulthood intussusception in Taiwan. Pediatr Neonatol 2013;54(3):188-193

5 Lindor RA, Bellolio MF, Sadosty AT. Earnest F IV, Cabrera D. Adult intussusception: presentation, management, and outcomes of 148 patients. J Emerg Med 2012;43(1):1-6

6 Das MK, Arora NK, Gupta B, et al. Intussusception in children aged under twoyearsin India: retrospective surveillance at nineteen tertiary care hospitals. Vaccine 2020;38(43):6849-6857

7 Hwang S, Kim J, Jung JY, et al. The epidemiology of childhood intussusception in South Korea: an observational study. PLoS One 2019;14(12):e0219286

8 Takeuchi M, Osamura T, Yasunaga $H$, Horiguchi $H$, Hashimoto H, Matsuda S. Intussusception among Japanese children: an epidemiologic study using an administrative database. BMC Pediatr 2012;12:36

9 Zhao L, Feng S, Wu P, Lai XH, Lv C, Chen G. Clinical characteristics and surgical outcome in children with intussusceptions secondary to pathologic lead points: retrospective study in a single institution. Pediatr Surg Int 2019;35(7):807-811

10 Banapour P, Sydorak RM, Shaul D. Surgical approach to intussusception in older children: influence of lead points. J Pediatr Surg 2015;50(4):647-650

11 Ekenze SO, Mgbor SO, Okwesili OR. Routine surgical intervention for childhood intussusception in a developing country. Ann Afr Med 2010;9(1):27-30

12 Pandey A, Singh S, Wakhlu A, Rawat J. Delayed presentation of intussusception in children-a surgical audit. Ann Pediatr Surg 2011;7(4):130-132

13 Satter SM, Aliabadi N, Yen C, et al. Epidemiology of childhood intussusception in Bangladesh: Findings from an active national hospital based surveillance system, 2012-2016. Vaccine 2018;36(51):7805-7810

14 Carapinha C, Truter M, Bentley A, Welthagen A, Loveland J. Factors determining clinical outcomes in intussusception in the developing world: experience from Johannesburg, South Africa. S Afr Med J 2016;106(2):177-180
15 Barbette P, Ouevres Chirurgiques at Anatomiques. Geneva, Switzerland: Francois Miege; 1674

16 de Moulin D. Paul Barbette, M.D.: a seventeenth-century Amsterdam author of best-selling textbooks. Bull Hist Med 1985;59(4):506-514

17 Velse $\mathrm{CH}$, De mutuo intestinorum ingressu. Lugduni Batavorum: J Luzac; 1742

18 Ellis $\mathrm{H}$. The first operation for intussusception. J Perioper Pract 2008;18(4):173-174

19 Thompson WW. A case of intussusception in which an operation was successfully resorted to by John R William. Transylvania J Med Assoc Sci 1836;8:486-487

20 Swain V. Sir Jonathon Hutchinson 1828-1913: his role in the history of intussusception. J Pediatr Surg 1980;15(2):221-223

21 Hutchinson J. A successful case of abdominal section for intussusception; with remarks on this and other methods of treatment. Med Chir Trans 1874;57:31-75

22 Hirschsprung H. Et Tlhfaelde af Subakut Tarminvagination. Hosp Tid 1876;3:321-327

23 Hirschsprung H. Hundertundsieben falle von Darminvagination bei Kindern, behandelt im Konigin Louisen-Kinderhospital in Kopenhagen wahrend der Jahre 1871-1904; kurz tabellarische Darstellung. Mitt Grenzgeb Med Chir 1905;14:555-574

24 Ein SH, Alton D, Palder SB, Shandling B, Stringer D. Intussusception in the 1990s: has 25 years made a difference? Pediatr Surg Int 1997;12(5-6):374-376

25 Wong CW, Chan IH, Chung PH, et al. Childhood intussusception: 17-year experience at a tertiary referral centre in Hong Kong. Hong Kong Med J 2015;21(6):518-523

26 Simon NM, Joseph J, Philip RR, Sukumaran TU, Philip R. Intussusception: single center experience of 10 years. Indian Pediatr 2019;56(1):29-32

27 Savoie KB, Thomas F, Nouer SS. Langham MR Jr, Huang EY. Age at presentation and management of pediatric intussusception: a Pediatric Health Information System database study. Surgery 2017;161(4):995-1003

28 Thanh Xuan N, Huu Son N, Huu Thien H. Treatment outcome of acute intussusception in children under two years of age: a prospective cohort study. Cureus 2020;12(4):e7729

29 Fahiem-Ul-Hassan M, Mufti GN, Bhat NA, et al. Management of intussusception in the era of ultrasound-guided hydrostatic reduction: a 3-year experience from a tertiary care center. J Indian Assoc Pediatr Surg 2020;25(2):71-75

30 Flaum V, Schneider A, Gomes Ferreira C, et al. Twenty years' experience for reduction of ileocolic intussusceptions by saline enema under sonography control. J Pediatr Surg 2016;51(1):179-182

31 Trigylidas TE, Hegenbarth MA, Patel L, Kennedy C, O'Rourke K, Kelly JC. Pediatric emergency medicine point-of-care ultrasound for the diagnosis of intussusception. J Emerg Med 2019;57(3):367-374

32 Wong CW, Jin S, Chen J, Tam PK, Wong KK. Predictors for bowel resection and the presence of a pathological lead point for operated childhood intussusception: a multi-center study. J Pediatr Surg 2016;51(12):1998-2000

33 Menke J, Kahl F. Sonography-guided hydrostatic reduction of ileocolic intussusception in children: analysis of failure and success in consecutive patients presenting timely to the hospital. Eur J Pediatr 2015;174(3):307-316

34 Ntoulia A, Tharakan SJ, Reid JR, Mahboubi S. Failed intussusception reduction in children: correlation between radiologic, surgical, and pathologic findings. AJR Am J Roentgenol 2016;207(2):424-433

35 Ekenze SO, Mgbor SO. Childhood intussusception: the implications of delayed presentation. Afr $\mathrm{J}$ Paediatr Surg 2011;8(1):15-18 